

\title{
Pilotstudie GPS-trackers grote sterns van Utopia, Texel 2018
}




\section{Pilotstudie GPS-trackers grote sterns van Utopia, Texel 2018}

Auteur(s): $\quad$ Martin Baptist \& Mardik Leopold

Publicatiedatum: 19 december 2018

Dit onderzoek is uitgevoerd door Wageningen Marine Research in opdracht van en gefinancierd door het Ministerie van LNV, in het kader van het Beleidsondersteunend onderzoekthema 'Natuurambitie Grote Wateren in de praktijk' met projectnummer BO-11-018.01.005

Wageningen Marine Research Den Helder, december 2018

VERTROUWELIJK Nee

Wageningen Marine Research rapport C095/18 
Keywords: grote sterns, GPS-tracking, telemetrie, Waddenzee, buitendelta's

Opdrachtgever: Ministerie van LNV

T.a.v.: Marjan Datema

Dit rapport is gratis te downloaden van https://doi.org/10.18174/466161

Wageningen Marine Research verstrekt geen gedrukte exemplaren van dit rapport.

Wageningen Marine Research Wageningen UR is ISO 9001:2015 gecertificeerd.

\section{(C) 2016 Wageningen Marine Research Wageningen UR}

Wageningen Marine Research, onderdeel van Stichting Wageningen Research KvK nr. 09098104,

IMARES BTW nr. NL 8113.83.696.B16.

Code BIC/SWIFT address: RABONL2U

IBAN code: NL 73 RABO 0373599285
De Directie van Wageningen Marine Research is niet aansprakelijk voor gevolgschade, noch voor schade welke voortvloeit uit toepassingen van de resultaten van werkzaamheden of andere gegevens verkregen van Wageningen Marine Research opdrachtgever vrijwaart Wageningen Marine Research van aanspraken van derden in verband met deze toepassing.

Dit rapport is vervaardigd op verzoek van de opdrachtgever hierboven aangegeven en is zijn eigendom. Niets uit dit rapport mag weergegeven en/of gepubliceerd worden, gefotokopieerd of op enige andere manier gebruikt worden zonder schriftelijke toestemming van de opdrachtgever. 


\section{Inhoud}

$1 \quad$ Inleiding

1.1 Onderzoeksvraag

1.2 Methode

$2 \quad$ Resultaten pilot 2018

2.1 Broedsucces

7

2.2 Resultaten GPS tracking

2.3 Vervolg van de studie

$3 \quad$ Kwaliteitsborging

Literatuur

Verantwoording

Bijlage 1

GPS-tracks 


\section{$1 \quad$ Inleiding}

De zeegaten tussen de Waddeneilanden vormen de schakel tussen de Noordzee en de Waddenzee. Veel dieren van de Waddenzee migreren via de zeegaten naar de Noordzee en weer terug. Het gaat hierbij bijvoorbeeld om jonge platvissen, sommige schelpdieren, garnalen, zeehonden en bruinvissen. In de zeegaten liggen ondiepe zandbanken, daar neergelegd door het in-en uitademen van de Waddenzee met het getij. Deze buitendelta's vormen een bijzondere leefomgeving, met name voor vis, visetende vogels en zeezoogdieren. $\mathrm{Er}$ is nog maar weinig bekend over de ecologie van de buitendelta's, terwijl er wel ingrepen in worden gepleegd.

Met het oog op het nemen van verantwoorde besluiten wil het Ministerie van LNV inzicht en kennis hebben over de te verwachten ecologische effecten van ingrepen zoals baggeren en zandsuppleties in buitendelta's. In het kader van het BO-onderzoek Natuurambitie Grote Wateren (NAGW) is een meerjarig onderzoek gestart naar de beschermde broedvogel grote stern. Het NAGW-onderzoek spitst zich toe op de vraag waar precies de grote sterns zandspiering, haring en sprot voor hun kuikens vangen. Het onderzoek bestaat uit twee delen: het zenderen van grote sterns en het in kaart brengen van de distributie van zandspiering in buitendelta's. Deze rapportage beschrijft de resultaten van de pilot naar het zenderen van grote sterns in 2018.

\section{$1.1 \quad$ Onderzoeksvraag}

Nederland is van groot internationaal belang voor de grote stern Thalasseus sandvicensis en een groot deel van de biogeografische populatie broedt in een beperkt aantal kolonies in het Deltagebied en in het Waddengebied. De grote stern is een beschermde soort van Bijlage I artikel 4.1 van de Vogelrichtlijn die in Nederland vertaald is in de Wet Natuurbescherming. Op grond hiervan zijn diverse Natura 2000-gebieden aangewezen voor deze soort, waaronder de Waddenzee.

In het Waddengebied en aanliggende Noordzee vinden diverse activiteiten plaats waar beschermde kust- en zeevogels, zoals de grote stern, mogelijk hinder van kunnen ondervinden. Een voorbeeld hiervan zijn zandsuppleties ten behoeve van kustverdediging, die behalve in de vooroever nu ook in de buitendelta's van de eilanden worden uitgeprobeerd. Tijdens de broedperiode foerageren de grote sterns die broeden op de Waddeneilanden en Griend voornamelijk in vooroever en buitendelta's. Zij vliegen heen en weer om hun prooivissen stuk voor stuk naar hun kuiken(s) te brengen. Buitendelta's en ondiepe vooroevers zijn dus van groot belang voor deze soort.

In dit onderzoek is de hoofdonderzoeksvraag:

1. Welke specifieke delen van een buitendelta worden door broedende grote sterns benut om te foerageren, en waar liggen de overige foerageergebieden?

\subsection{Methode}

Omdat grote sterns grote afstanden op zee afleggen tijdens het foerageren is het bijzonder lastig om de foerageerlocaties te bestuderen in het veld. Er is daarom gekozen om gebruik te maken van GPStrackers.

In 2018 is een pilotstudie uitgevoerd naar het in kaart brengen van de foerageerlocaties van grote sterns. Vijf grote sterns zijn gevangen op hun nest en voorzien van een UvA-BiTS GPS-tracker. Voor deze trackers is gekozen omdat hiermee met hoge nauwkeurigheid hun foerageerlocatie kan worden bepaald. De trackers hebben een functionaliteit om binnen een geografisch afgebakende regio met hoge frequentie GPS-locaties op te slaan. Daarnaast registreren deze trackers ook temperatuur en 
versnellingen in drie dimensies, hetgeen gebruikt kan worden om hun foerageerduiken te identificeren. De trackers slaan de data op in het geheugen, dat vervolgens wordt uitgelezen door een ontvangststation dat in de kolonie staat opgesteld.

De grote sterns werden gevangen in de broedkolonie Utopia $\left(53.1240^{\circ} \mathrm{N} 4.8955^{\circ} \mathrm{E}\right)$ op Texel. Het aantal broedparen in $2014-2017$ bedroeg 2.736-7.103. Samen met de broedkolonie Wagejot $\left(53.0895^{\circ} \mathrm{N}, 4.8981^{\circ} \mathrm{E}\right)$ wordt het totaal aantal broedparen op Texel in 2014-2017 geschat op 7.0227.440 (Spaans et al. 2018). In de kolonie Utopia stond een webcam opgesteld (Hikvision DS2DE5174-A). Videobeelden met een resolutie van $1280 \times 720 \mathrm{p}$ werden met $6 \mathrm{fps}$ (frames per second) draadloos verzonden naar, en opgeslagen op, een Network Attached Storage. Beelden van de broedkolonie konden live worden bekeken maar ook achteraf worden afgespeeld.

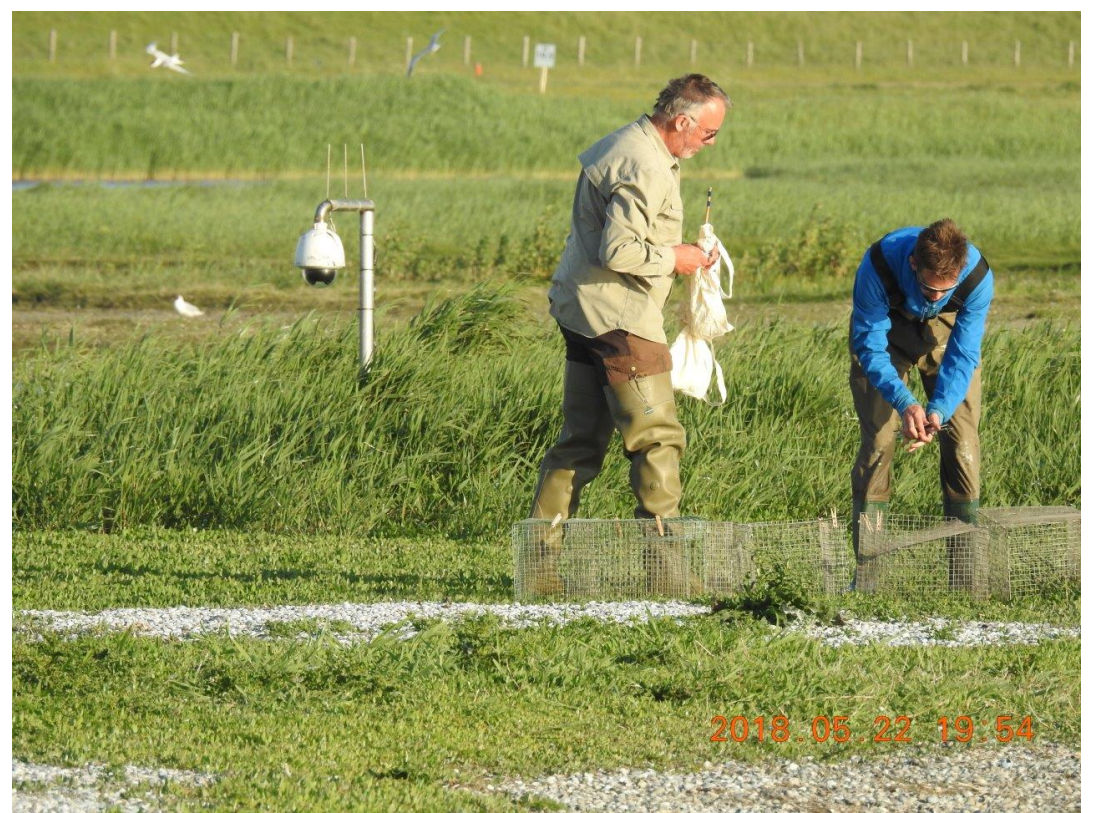

Figuur 1. Het plaatsen van vangkooien in het zicht van de webcam.

We vingen de grote sterns aan het eind van de broedperiode op het nest door middel van een vangkooi. De vanglocaties werden gekozen in het zicht van de webcam. Vijf individuen werden uitgerust met een GPS-tracker van UvA-BiTS (type 2CDSe, L:52 x W:22 x H:9 mm). De trackers hadden een gewicht van 7.3, 7.4, 7.4, 7.4 \& $7.5 \mathrm{~g}$. We selecteerden sterns zwaarder dan $250 \mathrm{~g}$ zodat het gewicht van de trackers niet meer dan $3 \%$ van het lichaamsgewicht van de vogels bedroeg. De vogels hadden een gewicht van 259, 263, 268, 274 \& $290 \mathrm{~g}$. De trackers werden aangebracht door middel van een permanent, geknoopt harnas bestaande uit ongeveer $50 \mathrm{~cm}$ teflon lint (Bally Ribbon Mills 8476-3/16" - Natural Tubular Teflon) met een binnenzijde van nylondraad 210d/24 en de uiteinden werden afgewerkt met TESA tape. De gezenderde sterns werden tevens voorzien van een stalen ring en een afleesbare kleurring. Eén van de gevangen vogels had al een stalen ring.

Voor het vangen en aanbrengen van GPS-trackers is een vergunning voor de Wet op de Proefdieren verkregen.

Tabel 1. Nummer van de tracker, kleurring code, stalen ring code en gewicht van de vijf gezenderde grote sterns.

\begin{tabular}{llll} 
Tracker nr. & Kleurring code & Stalen ring code & Gewicht $(\mathrm{g})$ \\
\hline 2415 & B-T00 & NL4402 & 274 \\
2414 & B-T01 & NL4404 & 259 \\
2420 & B-T02 & NL4405 & 263 \\
2416 & B-T03 & NLA1432434 & 290 \\
2419 & B-T04 & NL4410 & 268
\end{tabular}


Er werden twaalf controlevogels gevangen en geringd met een gewicht van 234, 239, 239, 239, 241, $241,242,250,258,258,260$ en $269 \mathrm{~g}$. Omdat (aanvankelijk) de zwaarste vogels een zender kregen, waren deze gemiddeld iets zwaarder dan de controlevogels: gemiddeld wogen de vijf gezenderde vogels $270.8 \pm 12.11$ gram en de twaalf controle vogels $247.5 \pm 11.12$ gram ( -test: $t=3.70, d f=15$, $\mathrm{P}<0.01)$. De controlevogels werden gevangen om het broedsucces van de gezenderde vogels te bepalen ten opzichte van een ongezenderde referentie.

Iedere tracker sloeg GPS posities op met 5 minuten interval tussen 05:00 en 15:00 UTC en met 15 minuten interval na 15:00 UTC tot de volgende ochtend. Een rechthoekig gebied in de zuidelijke Noordzee (coördinaat linksboven $53.5^{\circ} \mathrm{N} 3.8^{\circ} \mathrm{E}$, coördinaat rechtsonder $52.5^{\circ} \mathrm{N} 4.8^{\circ} \mathrm{E}$ ) was geprogrammeerd in de tracker voor het opslaan van hoge resolutie data. Wanneer een stern zich bevond binnen deze rechthoek (geofence) tussen 05:00 and 13:00 UTC werd hoge resolutie data opgeslagen. Dit tijdvenster was zo gekozen dat de accu's van de trackers 's ochtends voldoende tijd hadden om op te laden (1,5 uur na zonsopkomst) en dat er 's middags voldoende tijd was om een mogelijk leeggelopen accu weer helemaal vol te laden (6,5 uur tot aan zonsondergang). Vanwege het pilotkarakter van de studie werden initieel drie verschillende hoge resolutie programma's toegepast binnen het geofence. Eén tracker was geprogrammeerd om GPS posities op te slaan met $4 \mathrm{~s}$ interval, waarbinnen $1 \mathrm{~s}$ accelerometer data werd verzameld. Twee trackers werden geprogrammeerd om GPS posities op te slaan met $13 \mathrm{~s}$ interval waarbinnen $10 \mathrm{~s}$ accelerometer data werd verzameld. En twee andere trackers werden geprogrammeerd om GPS posities op te slaan met $32 \mathrm{~s}$ interval waarbinnen 2 series van $10 \mathrm{~s}$ accelerometer data werden verzameld.



Figuur 2. Met de klok mee van links boven: basisstation voor GPS-trackers, grote stern na aanbrengen tracker, nestmarkering, grote stern met tracker op nest, controlevogel met kleurring (Blauw-T09) en kuiken. 


\section{Resultaten pilot 2018}

\section{$2.1 \quad$ Broedsucces}

Vogel 2419 is direct na het aanbrengen van de GPS-tracker op 23 mei 2018 in een hoekje van de kolonie gaan staan (visueel waargenomen door Mardik Leopold) en is na enkele uren weggevlogen. Zijn/haar partner heeft nog tot en met 31 mei op het nest gezeten, maar daarna is er één ei in blijven liggen dat niet is uitgekomen. Deze vogel is ruim 2,5 maand later, op 12 augustus 2018, dood gevonden op het strand van Rockanje. De zender is niet teruggevonden en dus zijn er geen zendergegevens bekend van deze vogel.

Bij vogel 2416 is de tracker kapot gegaan direct na het aanbrengen. Deze vogel werd waargenomen op het nest zonder dat er trackerdata werden ontvangen. De vogel is opnieuw gevangen op 25 mei 2018 en de tracker is vervangen, waarna de vogel niet meer is gezien op het nest. De vogel is nog wel één keer visueel waargenomen in de kolonie op 6 juni door Mardik Leopold, maar zonder dataoverdracht en dat duidt erop dat ook deze tracker kapot is gegaan. Er is één kuiken waargenomen die bij nest 2416 hoort dat is grootgebracht door de partner van vogel 2416 samen met een adoptieouder.

Vogel 2415 verliet na negen dagen, op 31 mei 2018, de kolonie en deze heeft nog één keer een touch and go gemaakt, te weten op 8 juni (de tracker maakte contact met het basisstation, maar te kort om data over te sturen). De partner heeft de nestzorg voortgezet en we zagen één kuiken.

Van vogel 2414 hebben we GPS-tracks kunnen volgen tot en met 26 juni. Deze vogel heeft nooit kuikens gevoerd op het nest. Vogel 2414 is een vrouwtje zagen we op 5 juni tijdens copuleren.

Vogel 2420 is in de kolonie gebleven tot en met 30 juni. Het nest was goed te zien op de webcam en deze vogel heeft regelmatig vis gevoerd aan één kuiken. De vogel is op 21 september 2018 levend gezien in Boulogne sur Mer, Pas de Calais, Frankrijk, Figuur 2.

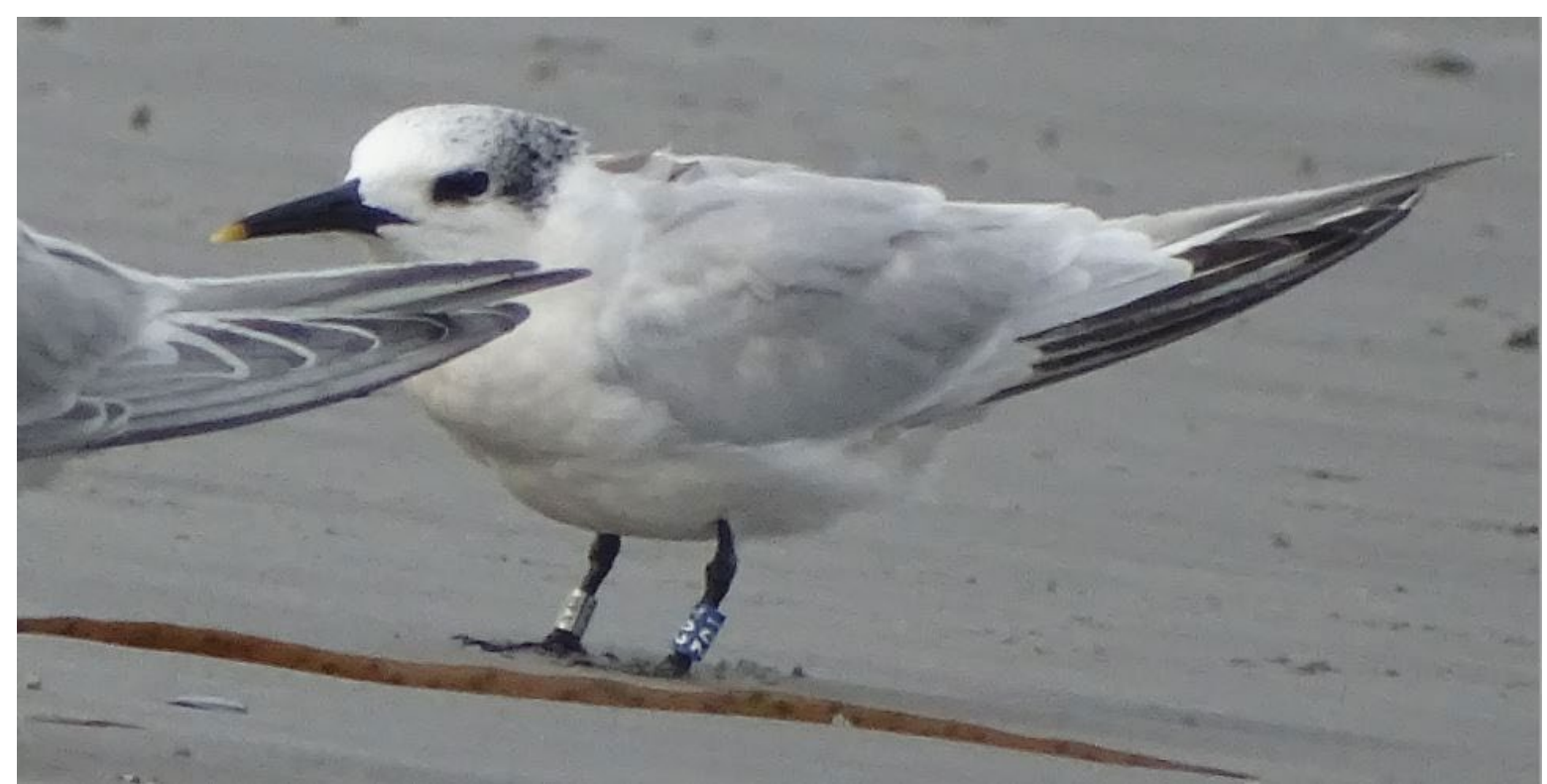

Figuur 3. Vogel 2420 met kleurring blauw T02 op het strand van Boulogne sur Mer, d.d. 21 september 2018. Foto: Eric Petit-Berghem.

Naast vijf vogels met GPS-trackers, een stalen "Vogeltrekstationring" en een kleurring hebben we 12 controlevogels voorzien van alleen een stalen ring en een kleurring. Alle controlenesten zijn altijd bezet geweest door één of twee sterns. We hebben in 7 van de 12 controlenesten kuikens 
waargenomen. Van elf van de twaalf controlevogels zijn kleurringen afgelezen in Utopia, een vogel is nooit gezien. Drie vogels zijn ook buiten Utopia waargenomen (peildatum 1 november 2018). Van de vijf vogels met een GPS-tracker zijn er vier in Utopia gezien (de kleurringen) en twee buiten Utopia.

Het aantal kuikens van de gezenderde vogels ( 3 broedsels uit 5 nesten $=60 \%$ ) kwam overeen met het broedsucces van de controlevogels ( 7 broedsels uit 12 nesten $=58 \%$ ) en van de gehele kolonie ( 2771 broedsels uit 4136 nesten $=67 \%$ ).

\subsection{Resultaten GPS tracking}

Van de drie gezenderde sterns waar GPS-tracks van zijn vastgelegd zijn zogenaamde 'heatmaps' gemaakt. De heatmaps zijn samengesteld op basis van GPS-locaties die zich boven zee bevinden; rustplaatsen op land, op zandplaten en op boeien in zee zijn verwijderd. De kaarten geven daarmee aan op welke locaties er vliegende sterns zijn geregistreerd. Op de locaties waar sterns relatief langdurig verbleven is met grote waarschijnlijkheid gefoerageerd. De eenheid van een heatmap is een Kernel Density Estimate, een maat voor de kans op voorkomen van een vogel. Rond iedere GPSlocatie is een cirkel met een straal van 500 m toegepast met daarbinnen een kansdichtheidsfunctie (volgens Epanechnikov) met een afnemende kansdichtheid naar de rand. De kansdichtheid neemt cumulatief toe bij meerdere waarnemingen bij elkaar in de buurt. Contourlijnen zijn aangegeven voor de $25 \%$ en $50 \%$ omhulling voor de totale kansdichtheid.

De binnenste contourlijn (25\%) van de heatmaps geeft de 'vlekken' waarbinnen de sterns hun belangrijkste foerageergebieden hebben. Het eerste dat opvalt is het gebruik van de Waddenzee onder Vlieland. Dit gebied kent ondiepe geulen in een zandig substraat en is vlakbij de kolonie van Utopia gelegen. Daarnaast wordt er vaak gefoerageerd aan de noordzijde van Vlieland, zowel aan de wadzijde als aan de noordzeezijde. Er wordt ook gefoerageerd in de buitendelta van het Eierlandse Zeegat, maar bijna uitsluitend aan de kant van Vlieland. Daarnaast is ook de noordwestzijde van Terschelling, en de zee tussen Engelschhoek en Terschelling, een foerageerlocatie. Het Amelanderzeegat werd ook een aantal malen bezocht door Texelse sterns. Hier werd vooral vlak ten westen van Ameland en in het noordelijke gedeelte van de buitendelta gefoerageerd.

Naast de heatmaps met samengestelde informatie zijn ook losse GPS-tracks van individuele sterns vervaardigd voor verschillende tijdvensters. Deze zijn weergegeven in de Bijlage. De foerageervluchten van de grote sterns strekten zich uit over een groot areaal. Sommigen vlogen heen en weer naar de zuidwestelijke delta van Nederland en een grote stern vloog helemaal naar het Duitse eilandje Minsener Oog. De grote sterns maakten ook lange offshore foerageervluchten boven de Noordzee. Hierbij viel op dat ze rusten op boeien en van hieruit kortere foerageervluchten ondernemen. De afgelegde afstanden waren dus fors, echter uit de resultaten van vogel 2420, die gevolgd kon worden tijdens de periode van het voeren van het kuiken, bleek dat gedurende deze periode de foerageervluchten dichtbij de kolonie werden uitgevoerd. 




Figuur 4. Heatmap voor de foerageervluchten van drie grote sterns in Waddenzee en Noordzee.

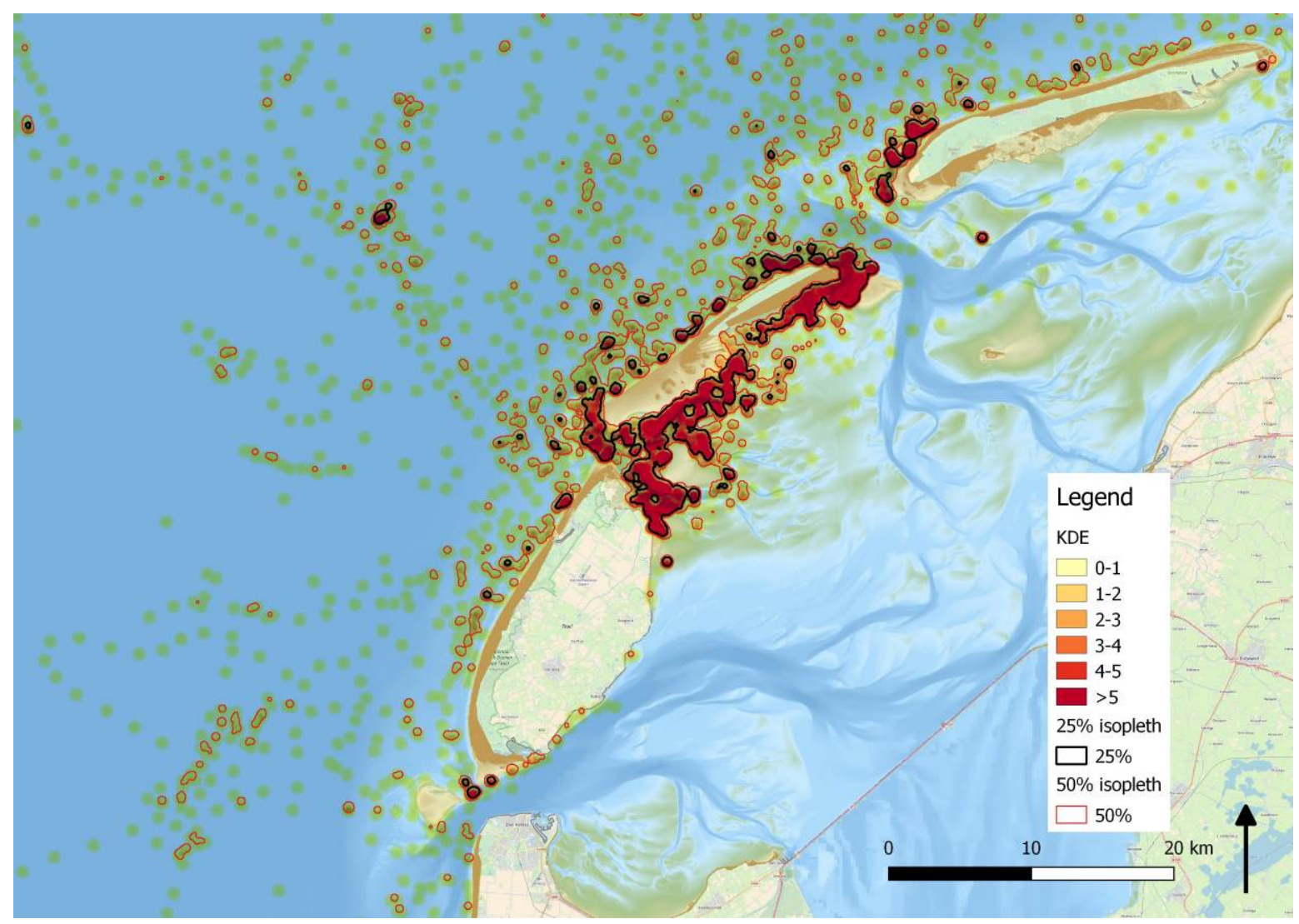

Figuur 5. Heatmap voor de foerageervluchten van drie grote sterns nabij Texel, Vlieland en Terschelling. 


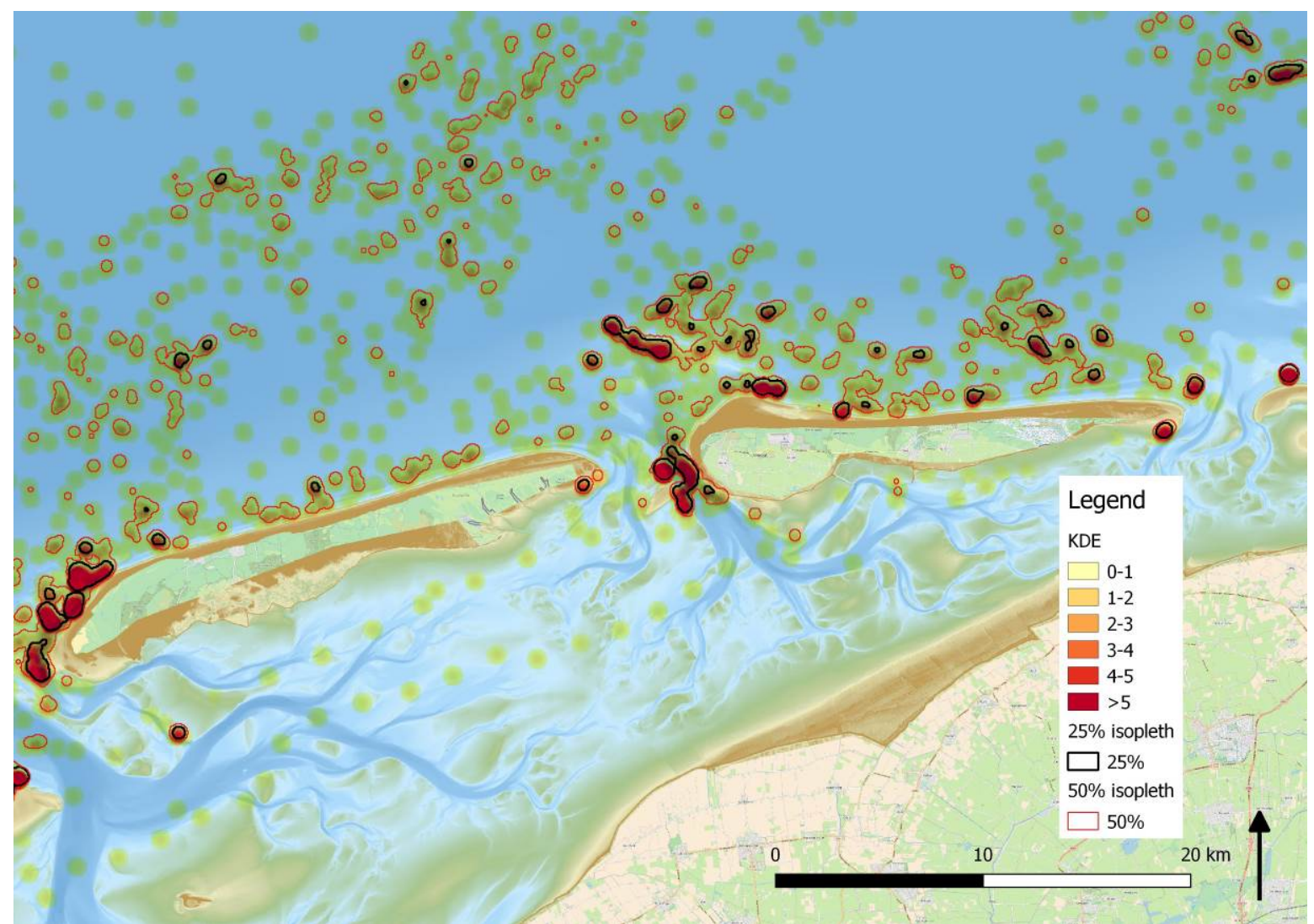

Figuur 6. Heatmap voor de foerageervluchten van drie grote sterns nabij Terschelling en Ameland.

\subsection{Vervolg van de studie}

De pilotstudie heeft laten zien dat de gebruikte onderzoeksmethode geschikt is om de foerageergebieden van grote sterns te bepalen. De gebruikte instellingen van de trackers leveren gedurende lange tijd GPS-posities in hoge resolutie. Naast GPS data kunnen de trackers ook accelerometer en temperatuurdata verzamelen. Deze informatie kan worden gebruikt om meer gedetailleerde informatie over het gedrag van de dieren te verzamelen, zoals het aantal foerageerduiken. In 2019 zullen 15 individuen worden voorzien van een GPS-tracker om hiermee de foerageerlocaties in de vooroever en buitendelta's nauwkeurig in kaart te brengen. 


\section{$3 \quad$ Kwaliteitsborging}

Wageningen Marine Research beschikt over een ISO 9001:2015 gecertificeerd kwaliteitsmanagementsysteem (certificaatnummer: 187378-2015-AQ-NLD-RvA). Dit certificaat is geldig tot 15 december 2021. De organisatie is gecertificeerd sinds 27 februari 2001. De certificering is uitgevoerd door DNV Certification B.V. 


\section{Literatuur}

Spaans B, Leopold M \& Plomp M (2018). Bepaling van het aantal nesten en het uitvliegsucces van Grote Sterns op Texel met behulp van een drone. LIMOSA 91 (1): 30-37. 


\section{Verantwoording}

Rapport C095/18

Projectnummer: 4318100200 BO43 18 NAGW Waddengebied

Dit rapport is met grote zorgvuldigheid tot stand gekomen. De wetenschappelijke kwaliteit is intern getoetst door een collega-onderzoeker en het verantwoordelijk lid van het managementteam van Wageningen Marine Research.

Akkoord:

ir. Sander Lagerveld

Onderzoeker

Handtekening:

Datum:

19-12-2018

Akkoord:

Drs. J. Asjes

Manager Integratie

Handtekening:

Datum:

19-12-2018 


\section{Bijlage 1 GPS-tracks}
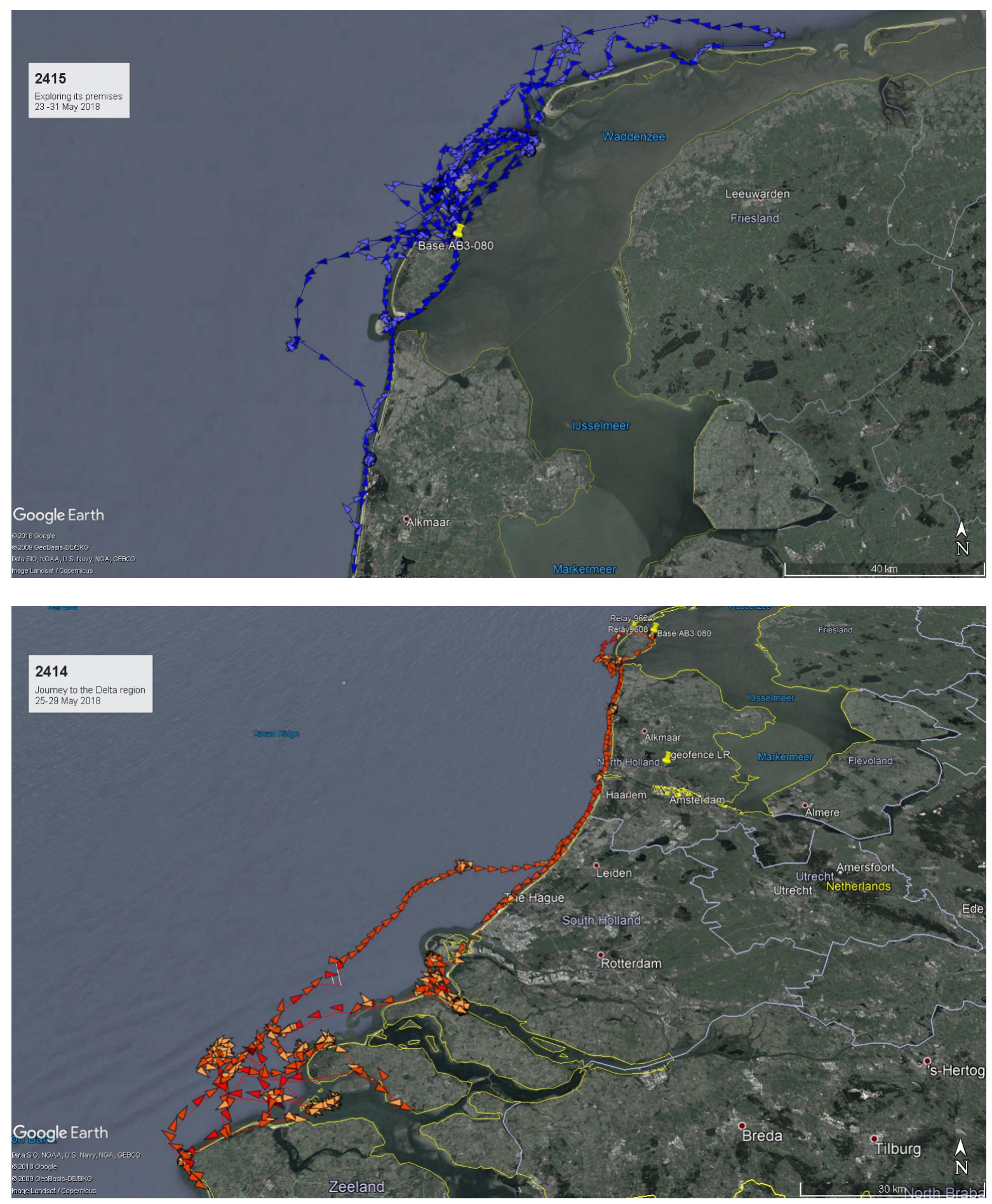

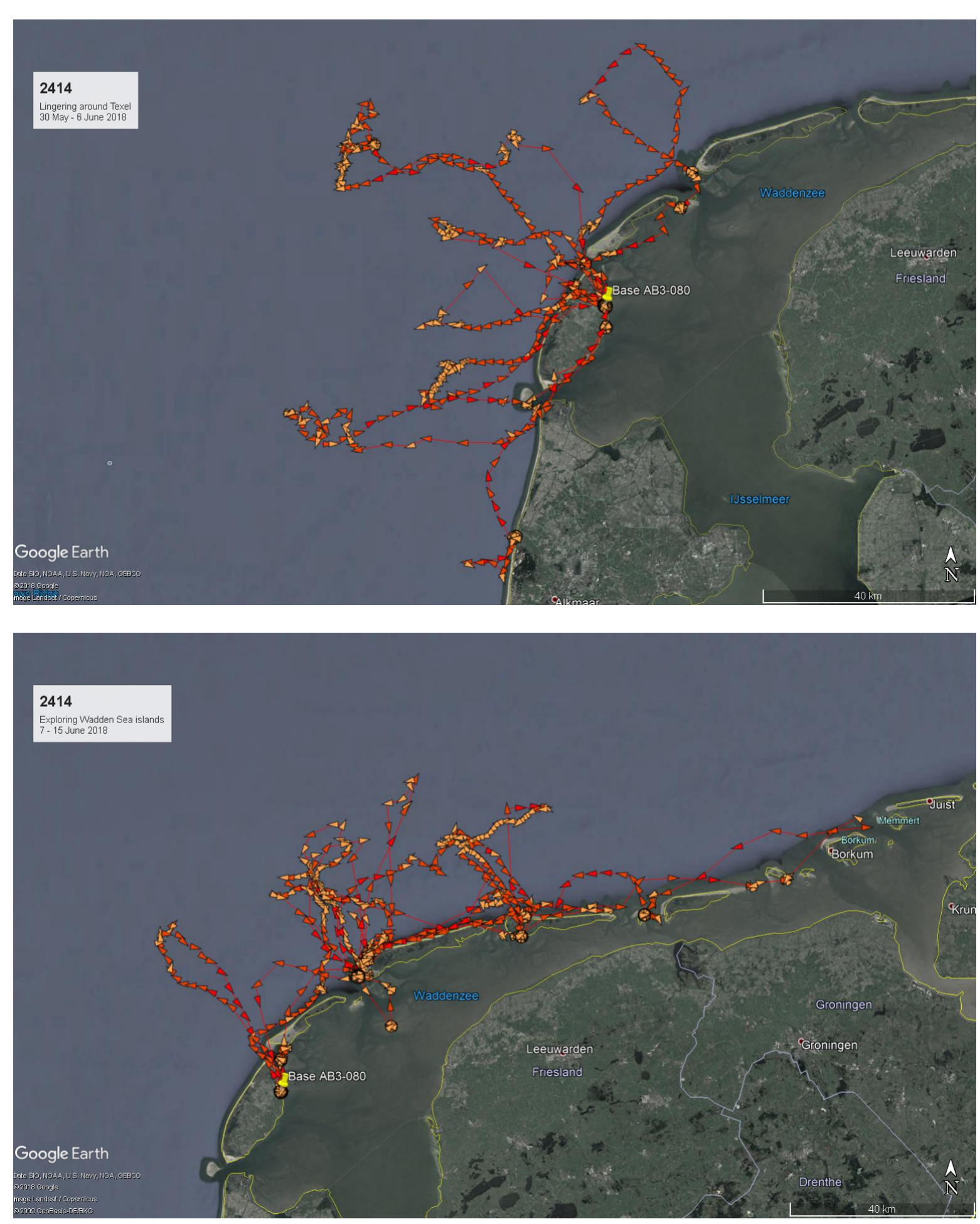

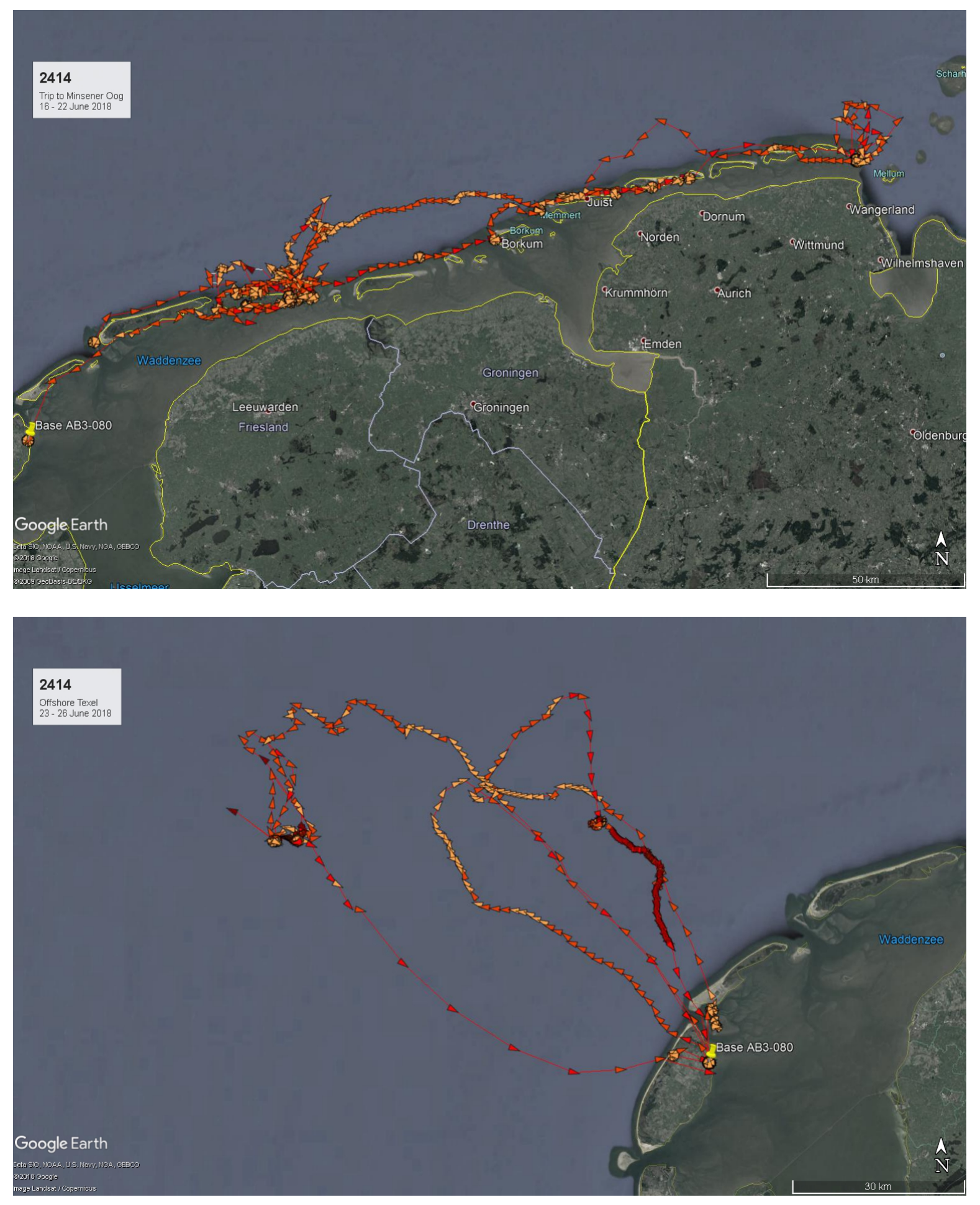

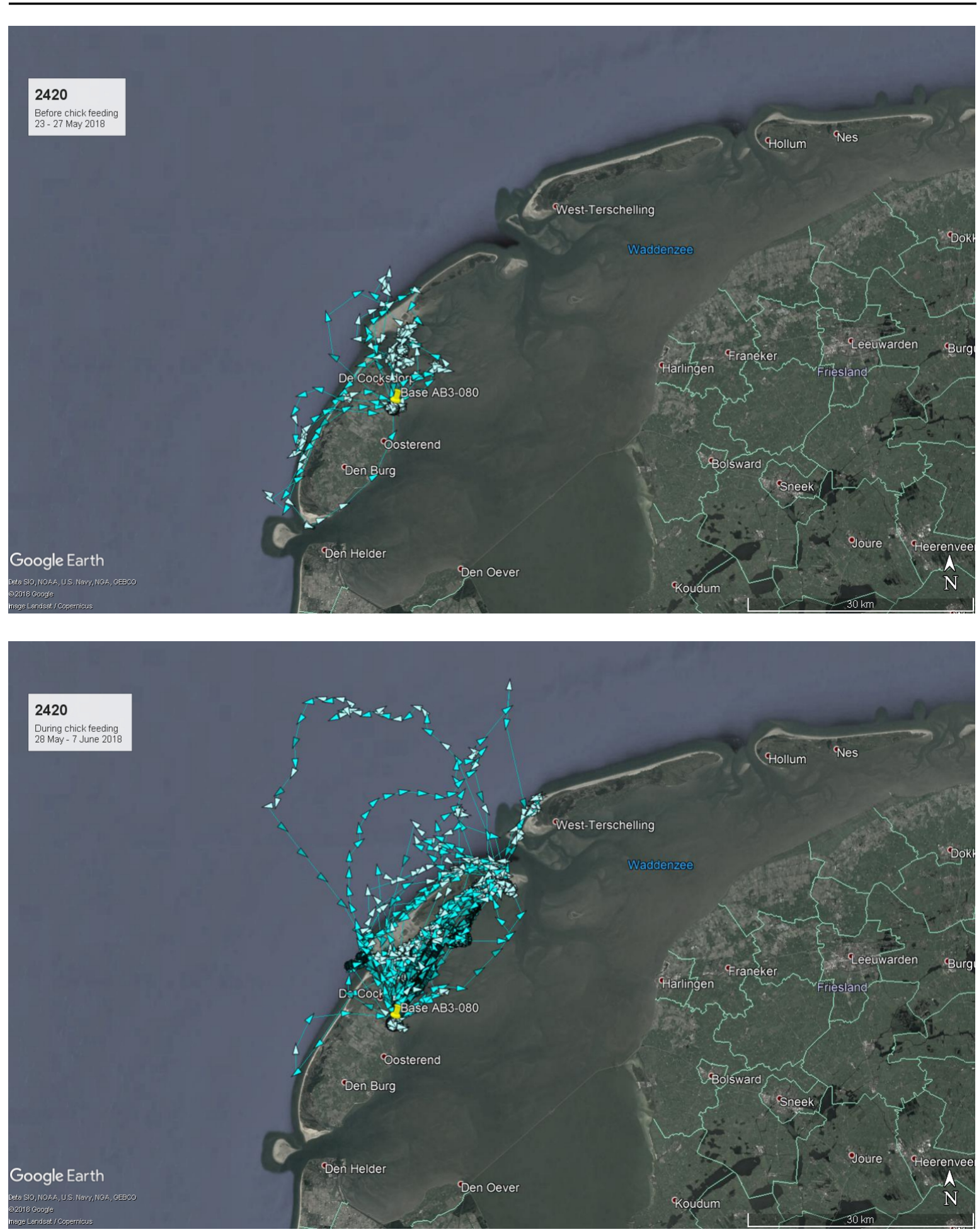

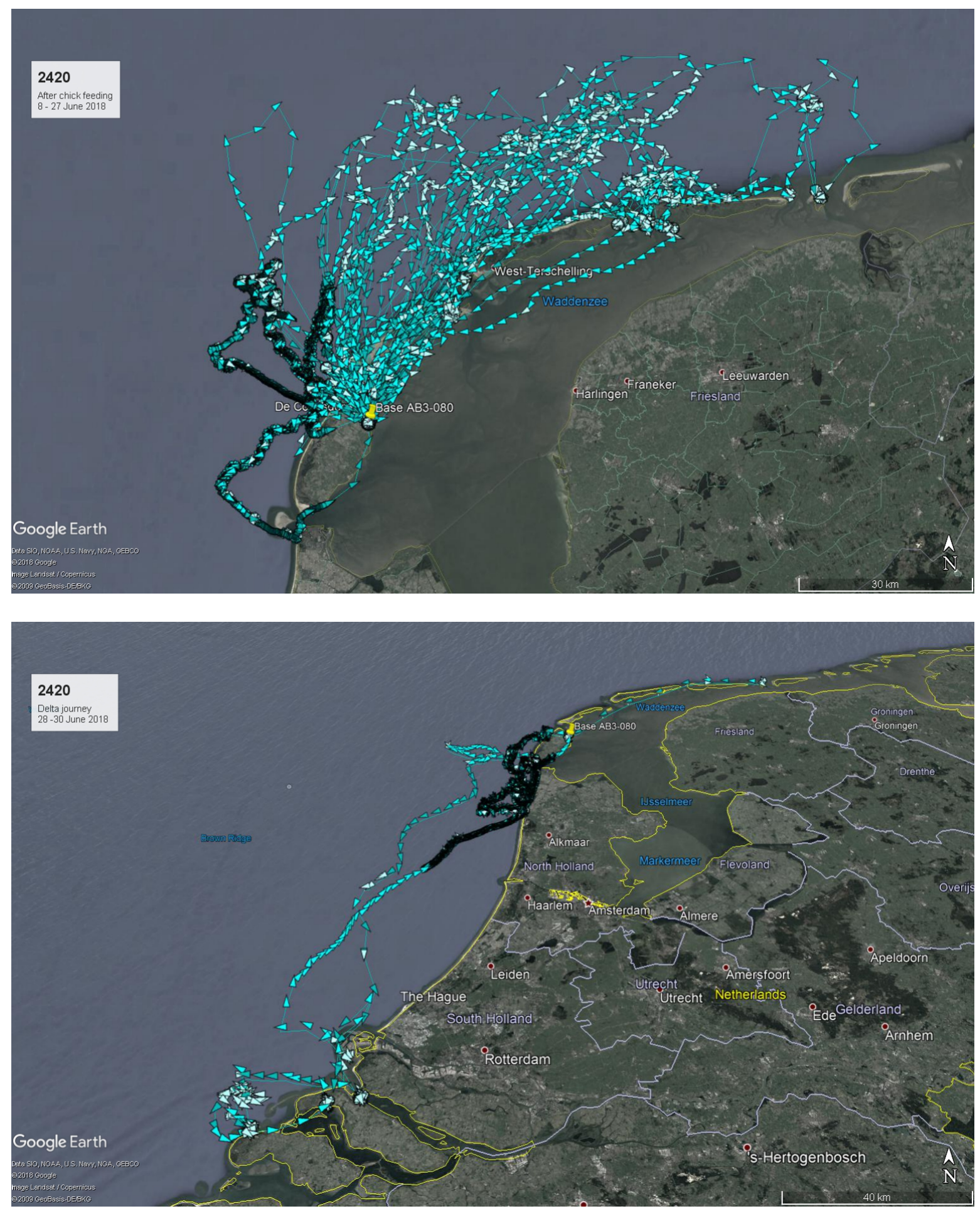
Wageningen Marine Research

$\mathrm{T}:+31(0) 317480900$

E: marine-research@wur.nl

www.wur.nl/marine-research

Visitors address

- Ankerpark 271781 AG Den Helder

- Korringaweg 7, 4401 NT Yerseke

- Haringkade 1, 1976 CP IJmuiden
Wageningen Marine Research is the Netherlands research institute established to provide the scientific support that is essential for developing policies and innovation in respect of the marine environment, fishery activities, aquaculture and the maritime sector.

Wageningen University \& Research is specialised in the domain of healthy food and living environment.

\section{The Wageningen Marine Research vision:}

'To explore the potential of marine nature to improve the quality of life.'

\section{The Wageningen Marine Research mission}

- To conduct research with the aim of acquiring knowledge and offering advice on the sustainable management and use of marine and coastal areas.

- Wageningen Marine Research is an independent, leading scientific research institute.

Wageningen Marine Research is part of the international knowledge organisation Wageningen UR (University \& Research centre). Within Wageningen UR, nine specialised research institutes of Stichting Wageningen Research (a Foundation) have joined forces with Wageningen University to help answer the most important questions in the domain of healthy food and living environment. 